\title{
11
}

\section{Heritage and Place: Kate Fagan's Diamond Wheel and Nancy Kerr's Twice Reflected Sun}

\author{
Jill Stubington
}

At the 2003 BBC Radio 2 Folk Awards Kazuo Ishiguro encapsulated so beautifully some of the things many of us felt it timely to question about heritage, repertoire and national identity in English vernacular music, questions the folk community was then exploring with increasing depth and articulacy, albeit often in musical form rather than verbally ... Place and heritage are so complexly felt, and so individually. (Kerr 2014a)

At the beginning of the 1970s, after three years of course work at Indiana University, Stephen Wild came to the Music Department of Monash University, joining the three ethnomusicologists already there: Trevor Jones, Alice Moyle, and Margaret Kartomi. I was on the staff at the time as Alice Moyle's research assistant, but I was also undertaking preliminary course work to prepare for graduate research. Waiting for the development of courses in ethnomusicology in the Music Department, I had done three years of undergraduate coursework in social anthropology. When ethnomusicology courses started, the four ethnomusicologists presented a wide-ranging set of courses with sometimes radically different theoretical positions. Stephen ran a lively and engaging honours seminar that took us through a set of readings of seminal works in ethnomusicology. During those years he became my teacher and friend. 
There are flashes in memory: long, late-night sessions where we explored the intriguing similarities and differences between the anthropology Stephen had been taught in America, and the social anthropology of the British tradition that I met at Monash; the visiting scholars who came through-Alan Merriam, Bruno Nettl, William Malm, David McAllester; the Warlpiri man who came to work with Stephen on song texts and needed help buying clothes for his wife; the carefully selected colour slides and sound recordings from Hooker Creek, as it was then, that Stephen showed us; the delightful puppy that Stephen called Erich von Hornbostel.

The overwhelming memory, however, is of the constant bubbles of excitement arising from the newness of the ideas we were discussing: the spine-tingling induced by the awareness that these were profound and experimental ways of thinking about music. The years since then have produced a steady flow of solid work from the students of that place and time and their students. Stephen's teaching and his open and supportive approaches to research have been enormously influential in Australian ethnomusicology. Those early experiences have remained a constant ground throughout my life. Thank you, Stephen.

\section{Introduction}

Early in 2010 I bought two CDs: Kate Fagan's Diamond Wheel (2007) with performances of 12 songs she wrote herself, and Nancy Kerr and James Fagan's Twice Reflected Sun (2010) with performances of nine of Nancy's songs, and two tracks of James's tunes. ${ }^{1}$ Listening to these two CDs in subsequent weeks and months, I found myself more and more delighted by their sophistication and accessibility, neither characteristic impaired by the other. Later that year I attended the National Folk Festival in Australia and heard further performances of some of these songs.

Listening and observing, I was struck by how specifically the singers explore and musically investigate chosen aspects of the lived reality of their lives, and within that lived reality, how similar and how different Kate's and Nancy's songs are. Nancy Kerr's observation about the

1 Both Kate and Nancy come from families of musicians who share their surnames. To avoid ambiguity and to bypass the clumsiness of using their full names every time, I will refer to them using their given names. 
complexity of heritage and place, and the current questions in the English folk community about heritage, repertoire, and national identity seemed to me to resonate very clearly with the way I was reacting to these songs. In this chapter I will examine these performances and isolate some aspects of the way I perceive significance and meaning in these songs through the concepts of heritage and place. I will also reflect upon Indigenous Australian perceptions of identity and place in relation to this very different musical tradition and raise some questions about what constitutes an Australian identity in music.

\section{Theoretical orientation}

Before I start this examination of heritage and place in relation to these songs, however, I need to clarify which current strands of ethnomusicological theory I am using and which aspects of recent work on heritage and place I am drawing upon.

\section{Ethnomusicology}

I will be coming from an ethnomusicological perspective that views meaning and significance as arising in emplaced and embodied musical performance. Elizabeth Mackinlay explores these issues in her paper 'Memories in the Landscape: The Role of Performance in Naming, Knowing, and Claiming Yanyuwa Country' (2006). Ethnomusicology has long regarded the musician's and the listener's perceptions as of equal importance in the production of musical meaning and significance. The physical and material production of sound in singing and playing, rooted in the culturally circumscribed being of the performers, meets the listening and watching of the culturally circumstanced audience. Intellectual, aesthetic, and emotive responses to the performance arise in particular times and in particular places. Important to this description is the notion that culture is continually being reworked and redefined in individual and shared experiences. Musical events draw on and manipulate individual histories, experiences, and orientations producing shared moments of physical delight. My account will therefore be of necessity personal and somewhat outside the traditional nature, style, and tone of much academic writing. 


\section{Music perception}

More attention is now being paid to the processes involved in listening and perception of music, and some of it is very challenging to traditional musicology. The new conclusions about listening and musical perception force a new honesty. In showing that musical perception is essentially dependent on the potentially very different way each listener perceives the sounds, they directly challenge writing that purports to be objective. The view being challenged, a now somewhat old-fashioned view in musicology, is that music analysis is an independent, autonomous activity; that a proper analysis will demonstrate how the composer/performer constructed the music; that patterns that show up in analysis must have been deliberately put there in the process of composition. The old assumption was that there is a tight, determinative relationship between pitch and frequency. Because frequency could be measured precisely, and because pitch was considered to be in a one-to-one relationship to frequency, it used to be assumed that pitch was similarly capable of very precise definition. This, we now know, is not so. Contemporary neuroscientific research does not support it. On the contrary, it defines music perception or pitch as the end result of the as yet imperfectly understood activity in the brain by which a listener processes sonic material: 'The crucial link between neural activity and the psychological percept remain $[s i c]$ unexplored' (Schnupp and Bisley 2006).

The year in which I did little else but notate northeast Arnhem Land clan songs showed me the deficiencies of the positivist view. I often found that when I went back to check notations I had done previously, often only the night before, I would perceive the music differently from the way I had first heard it. The recording had not changed, but my perception changed with new listening circumstances. At that time, the late 1970s, my inescapable conclusion was that the perception of music is not determined solely by its sonic characteristics, but is also dependent on the context of the performance and the listener's stance.

Auditory neurosciences confirm this newer conclusion that pitch perception is a thoroughly contingent activity. Pitch is recognised as one of the most salient aspects of musical listening, but neuroscientists agree that perceived pitch is not a straightforward phenomenon. Stewart comments: 'Pitch is a percept, rather than a physical attribute of the sound stimulus and the exact relationship between the stimulus 
attributes and the percept is still debated' (Stewart et al. 2006: 2534). Physiologists Schnupp and Bisley (2006) agree: 'perceptually pitch has a great "immediacy", [but] physiologically pitch is a surprisingly complex phenomenon. It is sometimes said that the pitch of a sound is "related to its frequency content" but that relationship is anything but straightforward'. The perception of pitch remains unexplained even after considerable work has addressed it, and the perception of rhythm and tempo, which has attracted less attention, remains even more obscure. Stewart advises that 'the brain substrates underlying analysis of the temporal organisation of music (rhythm and metre) have been less thoroughly investigated compared with those that underlie pitch perception', and acknowledges the distance yet to travel: 'the musical listening experience is an emergent property that is greater than the sum of its parts' (Stewart et al. 2006: 2536). There is, in fact, no one correct way of perceiving music. This research supports my experience with musical notation. The process of notation does not produce an authoritative, definitive account of musical performance. It merely documents the way one particular listener heard the performance at one time.

\section{An ethnomusicological response to new theories of music perception}

Judith Becker teases out the implications that these conclusions have for musicology. In a book primarily directed at understanding the phenomenon of trance, she explores a process she calls 'deep listening' (Becker 2004). 'Deep listeners' is a term she uses to describe people who are 'profoundly moved, perhaps even to tears' while listening to music, 'people who share the ability to respond with strong emotional arousal to musical stimulation' (Becker 2004: 54). She acknowledges the view that musical meaning changes with space and time, and implicates 'not only structures of knowledge and beliefs but also intimate notions of personhood and identity' (ibid.: 70). She uses the term 'habitus of listening' to describe the way we listen.

Our 'babitus of listening' is tacit, unexamined, seemingly completely 'natural'. We listen in a particular way without thinking about it and without realizing that it even is a particular way of listening ... A 'habitus of listening suggests, not a necessity nor a rule, but an inclination, a disposition to listen with a particular kind of focus, to expect to experience particular kinds of emotion, to move with certain stylized 
gestures, and to interpret the meaning of the sounds and one's emotional responses to the musical event in somewhat (never totally) predictable ways. The stance of the listener is not a given, not natural, but necessarily influenced by place, time, the shared context of culture, and the intricate and irreproducible details of one's personal biography ... How we perceive a piece of music has everything to do with our own histories, our own set of experiences relating to that particular piece of music, our 'manner' of offering ourselves to an external stimulus. (Becker 2004: 71, 108)

Becker argues forcefully that conclusions about musical meaning will be hollow until the importance of the listener's stance is recognised and understood.

Until we can accept that to a large extent we construct our own world and act within that world on the basis of our own constructions and that those actions become a part of the meaning of the world and of all subsequent constructions, we are precluded from gaining insight into the phenomenology of either deep listeners or trancers. (Becker 2004: 112)

\section{Listening to Diamond Wheel and Twice Reflected Sun}

I played these two CDs, Kate Fagan's Diamond Wheel (Figure 1) and Nancy Kerr and James Fagan's Twice Reflected Sun (Figure 2), many times in the months after the National Folk Festival, and these songs resounded and re-echoed in my musical habitus. I would regard myself as a deep listener, but not a trancer. In a way that I find unavoidable, I began to interrogate the songs, to try to account for the emotionally transformative experiences I felt. Some part of the music and its affects always remains elusive, inexplicable, as the neuroscientists observe, but the recognition of some of the mechanisms by which the songs speak is a joy not to be missed. Nancy Kerr is not threatened by this acknowledgement of the listener's place. On the contrary she is delighted by it:

I love the way songs attain their truth and vigour in the ear of the beholder - my song Now is the Time I wrote to celebrate the actively peaceful people I know who keep art and justice alive in their thoughts and actions, but according to others it's a secular hymn or a song about climate change ... so perhaps it is. (Kerr 2014b) 


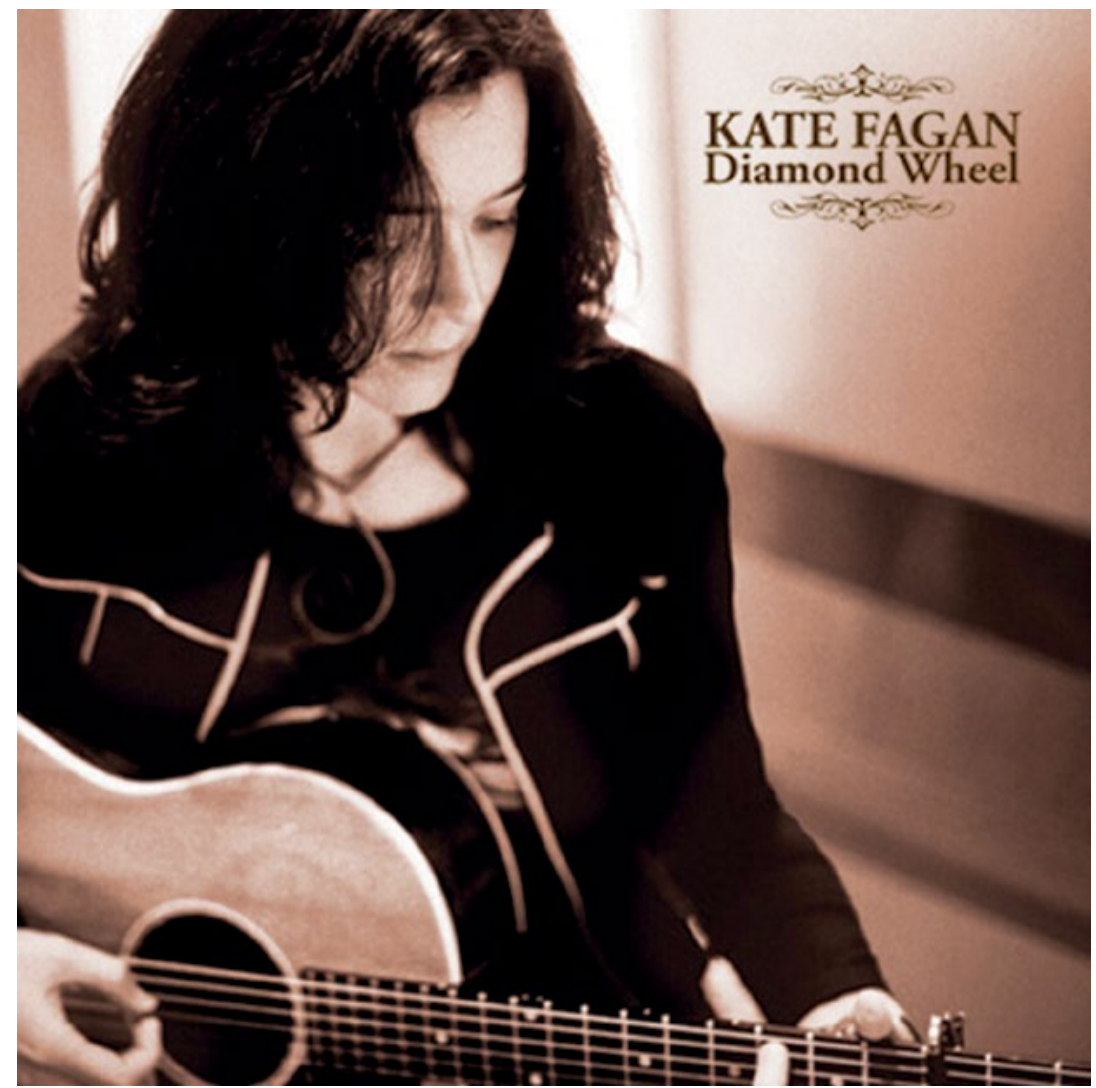

Figure 1. CD cover of Diamond Wheel by Kate Fagan (2007)

Source: Kate Fagan

The two frames for this account are heritage and place, and to the extent that it is possible, I will deal with them separately. 'Heritage', like 'tradition', is a highly contested concept. In this context, I am using it to refer to the relationship between a current performance and past performances. A performer who acknowledges a debt to heritage is taking a personal stance, which takes account of previous performances. In folkmusic contexts, performers reach back to historical recordings and earlier descriptive accounts. Performers may use older musical styles—repeating them, echoing them, or bouncing off them. This relationship may be seen in subject matter, musical style, and performance contexts. 


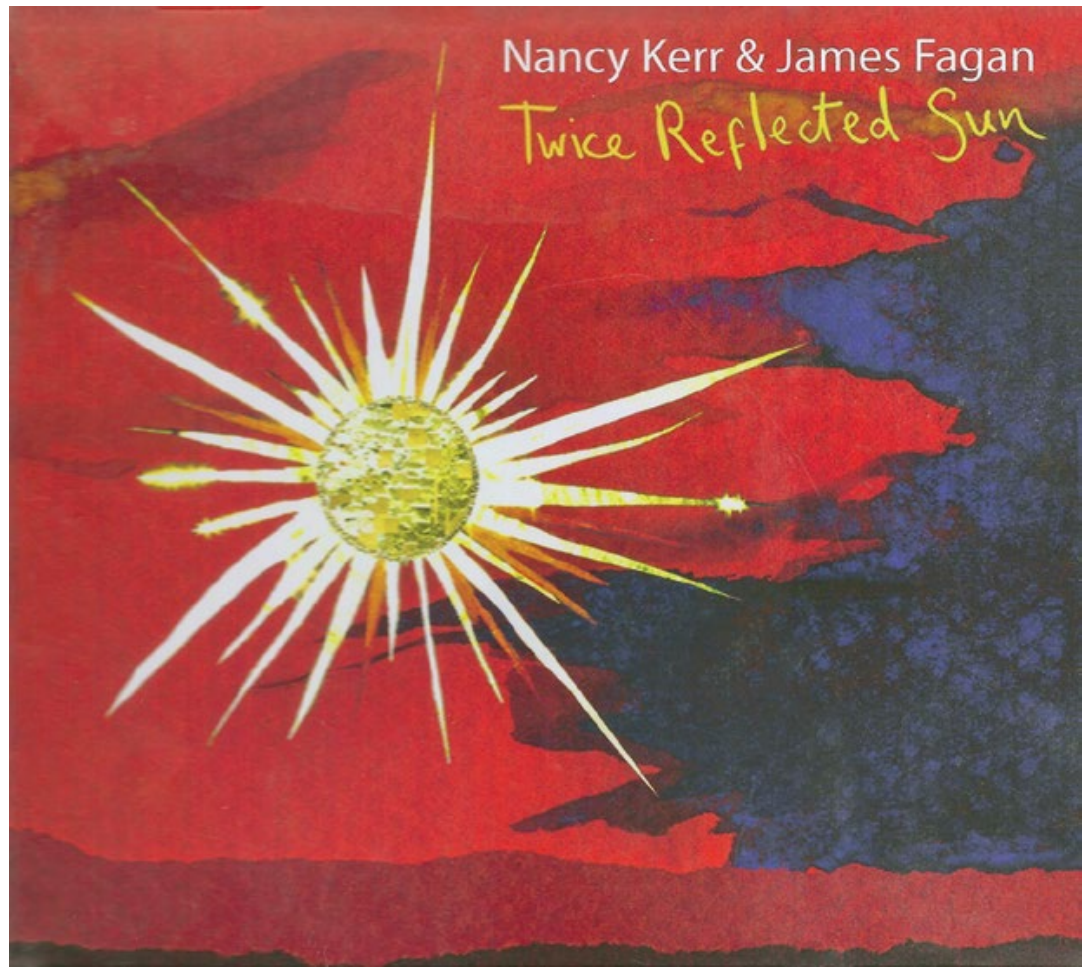

Figure 2. CD cover of Twice Reflected Sun by Nancy Kerr and James Fagan (2010)

Source: Nancy Kerr

This account of heritage will of necessity be incomplete, and it will also challenge current Australian folk music identifications and preoccupations. The current Australian 'folk milieu' has a tight definition of 'authenticity', and a neat and reductive understanding of identity that describes James Fagan as an expat, Nancy Kerr as a British tourist, and Kate Fagan as an American acolyte. On the other hand, I treat the material as music, rather than as an aspect of folklore and work outside the discipline of folklore. In my experience, the concept of identity has moved beyond such simple labelling. It is now recognised that personal identity is in a process of constant flux. It is continually being questioned, reworked, and renegotiated, and musical performance is one of the mechanisms of this negotiation. 
Nancy Kerr says: 'Personally, I'm not really interested in national identity' (Kerr 2014a), and in her 'list of traits in order of personal significance, English comes in at about number 14' (Kerr 2014c). Her musical heritage, she says, 'isn't a clean line; it's a briar whose roots are bidden, which twists confusingly, and which flowers at unexpected points' (Kerr 2014c). I think it is because the definition of Australian culture is at a very immature point, still attempting, not markedly successfully, to account simultaneously for Indigenous cultures, along with the many more recent immigrant cultures, that the identification of what it is to be Australian is so preoccupying. In spite of Nancy's lovely image of her musical heritage as a briar, it still seems from my Australian perspective that the presence of Indigenous cultures, so remarkably different from the immigrant cultures, means that Australian heritage is far more complicated than English heritage. Traditionally, Indigenous Australian music was radically different from the music of later immigrants in sound sources, structure, and status. Voice was by far the most important sound source, and other instruments were used almost entirely in accompaniment to singing. The musical structures consisted mostly of a series of short items threaded together to form a lengthy performance. Music was very important in traditional life, the ability to remember and sing the repertoire confirmed high standing, authority, and power on the singer. Song series were tied closely to particular defined places, and the well-being of place and of the people who belonged to it was considered to be ensured by singing the associated songs correctly and at the right time and place. How to recognise these beliefs and practices and acknowledge and properly value and engage with them in contemporary Australia is still ill-defined. We are still thinking about what it is to be Australian, and national identity is a real and troubling issue.

\section{The source performances}

On Wednesday, 9 March 2011, the Fagans gave a concert performance at Humph Hall, the new acoustic performance venue on Sydney's northern beaches. Wayne Richmond and Gial Leslie purchased the former Uniting Church at Allambie Heights, converting the church and the attached hall to a comfortable home. The church is now an attractive, intimate space in which Richmond's group, Loosely Woven, rehearses and performs. It is also in use for other local, national, and international folk music performances. About 80 people can listen there in comfort. 
The Fagans are Bob and Margaret; their two children, James and Kate; and James's wife, Nancy Kerr. My investigation here is based on the performances I witnessed and the extended listening to the two CDs that I did in subsequent weeks and months. In my discussion of the songs, I will be pointing out characteristics that I identify as originating in the musical heritage of the performers described here, but I also need to take account of my own musical heritage that undoubtedly colours my listening and to some extent determines how I perceive the songs.

\section{Aspects of the musical heritage of the performers}

Musically, the practices of both Kerr and Fagan families have grown out of Irish, English, Scottish, Australian, and to some extent, American folk music. Bob and Margaret Fagan have been regular and popular performers in Australia for many years. The strength of their repertoire is in their concern for social justice. Traditional and contemporary songs about working, freedom, justice, and equality figure prominently. Bob plays guitar, and both sing, together and separately. Margaret plays concertina and piano, but not often in performance. Bob's engaging baritone often has a lightness of touch and is tongue-in-cheek. Margaret's tensile soprano is well suited to the English traditional ballads she often sings.

Nancy Kerr's father was a Northumbrian piper and her mother, Sandra Kerr, is a well-known singer and concertina player who has lived for many years in Northumberland and has taken great delight in her deliberate exploration of Northumbrian traditional repertoire. Sandra has visited Australia several times and given concertina workshops associated with the National Folk Festival in Australia.

James has lived in England for many years, and performs with Nancy and with other groups. He sings and plays mainly bouzouki. Nancy sings and plays mainly fiddle. As a duo they are well known and highly awarded in Australia, Britain, continental Europe, and North America. James has a strong flexible voice, delivering texts with clarity and a deliciously Australian emphasis in accent and in choice of songs. Nancy has a clear voice very well trained in folk singing, and she uses it very purposefully. Both are fearsome instrumentalists whose skills are highly in demand. Kate is well known in Australia as a poet and a musician. She uses her singing voice with thoughtful expressivity and plays guitar, piano accordion, and piano with the same musical intensity. 


\section{Aspects of the musical heritage of the observer}

As every listener does, I bring a range of unusual and possibly quite individual musical and intellectual preoccupations to a performance. My original training was as a pianist, but there have been a couple of musical adventures since then that dominate my stance. The first was the experience of singing in Gordon Spearritt's Queensland University Madrigal Group as an undergraduate. A small vocal group, perhaps three voices to a part, we met twice a week in a room in which there were no instruments: we sang at sight and kept ourselves in tune without instrumental assistance. The major part of the repertoire were the madrigals, motets, balletts, and part-songs of late-sixteenth-century and early seventeenth-century England. Looking back, and it is a long way back to the mid-1960s, I think now that I was probably on a continuous high as an undergraduate from this sumptuous musical diet, and those songs resonate in my body and mind.

After graduating I became research assistant to Alice Moyle, one of the pioneers of musicological research into Australian Aboriginal music. This began a 48-year involvement with the lightly accompanied songs of Aboriginal Australians. During fieldwork in the mid-1970s, I observed and recorded northeast Arnhem Land manikay (clan songs), but for most of these years, my sources were sound recordings. Spending a year transcribing didjeridu- and stick-accompanied songs for a doctoral thesis, I learnt to listen in very particular and directed ways. Recordings for me are therefore not disembodied sound. I hear the body of the performer in the sound of the voice.

Consciousness of Aboriginal practices and the feeling of Aboriginal music that pervades my body are now never entirely absent. All I can hope for is that I can manipulate the collision in my thinking and habitus between Aboriginal and non-Aboriginal music so that it is productive, positive, and life-affirming. My listening and analysis are not perfectly complete, objective, and prototypical: no analysis is. Following Judith Becker's arguments outlined above, I agree that the way analysis is done and the issues treated are dependent on the analyst's orientation and perception. I have included as much of my background as I think would be necessary for a reader to properly situate my perceptions. By laying out my own orientations and experiences so clearly, I hope that the prejudices and preoccupations I bring to the listening and analysis outlined here would also be clear. 


\section{Musical heritage in the performances}

One of the first characteristics to jump out at me is the way in which these two CDs are alike in their relationship to earlier musical traditions. The nature and quality of this relationship reminds me of an expression I have heard used by Aboriginal and folk musicians: 'serving the tradition'. The expression highlights both respect for earlier performers and performances, and is a claim to be part of those traditions. Sometimes this is shown simply by musical style and sometimes people who are part of that tradition are actually named. Either case works well.

In the Australian country dances of the first half of the last century, waltzes were a favourite. Australian folk music collectors have recorded an extensive set of delightful waltz tunes (see John Meredith's collections (Meredith and Anderson 1967) and subsequent publications) and Kate's 'Old Station Sisters' is an easy fit with this repertoire. It has a sprightly diatonic melody whose harmonic implications are lightly and appropriately realised by plucked string instruments and piano accordion. Kate's voice sketches a shapely melody giving clear definition to the high notes, and tapering the lower ones away almost to a whisper. The quotation of 'The Mudgee Waltz' and the text that anchors the song to 'the '30s' place the song clearly in time and space. Singing the song in contemporary performances not only acknowledges the traditional repertoire, but places it at the service of contemporary 'musicking'. The text of the song describes a situation familiar to readers and singers looking for material about women's lives. The two sisters have somehow missed out on the path that would give them their own families, but they find salvation in the 'finest' and 'grandest' of dances, the waltz.

On the other hand, Kate moves to a very British song in 'Child upon the Road'. As 'The False Knight upon the Road', this song, with its question-and-answer form, appears in the canonic Child ballads (Child 1882-98). The history, meaning, and significance of the many versions of this song have been questioned and argued over, and the song recorded and performed for years. Kate has made a version of her own. In the more traditionally derived versions I have heard, the child stands his ground, and this is part of the child's virtue, along with his answers to the knight's (or devil's) questions. In Kate's version the child, whose gender is not specified, answers the questions and does not fall into the traps set. At the end, however, in the 14th verse, which Kate says she wrote to avoid leaving the song with 13 verses, the horses bolt and the child vows to avoid this 
dark road in future. Perhaps these are badlands in the sense that Ross Gibson explains in his Seven Versions of an Australian Badland: 'haunted by fear and tragedy, this stretch of country is an immense, historical crime scene ... old passions and violent secrets are lying around in a million clues and traces' (Gibson 2002: 1). Kate's version has a textual and musical refrain in each third and sixth line, and the music is beautifully constructed. It does not have the initial rising sixth that some versions have, but begins with the plain tonic, followed by the third and then the fifth in a single voice. The melody is mostly left to the single voice, with hummed accompaniment in the later verses, but the refrain lines are given more and more elaborate accompanying vocal parts, using seconds, fourths, sixths, and sevenths. As a Child ballad, there is no argument about its status as a folk song. Here, however, is a new version whose musical structure is entire modern.

These two songs exemplify Kate's imaginative resourcefulness in dealing with musical traditions. In 'Old Station Sisters', the tempo and musical structure of an Australian waltz give body and physicality to the themes of sisterhood, dresses, love, loss, and dancing. In interpreting 'The False Knight upon the Road' described above, Kate first of all brings the emphasis to the other participant. Her song is called 'Child upon the Road'. There are no instruments here. Singing voices show off both the artlessness of the child and the musical complexity that develops through the song and reinforces the child's increasing perspicacity. Unaccompanied singing in parts gives a pointed forcefulness, which Kate well understands from her own family's performances, if from nowhere else.

Nancy's conversation with tradition is equally lively. Her performance with James of 'Dance to Your Daddy', is not recorded on this CD, but was sung at the National Folk Festival in 2011. Nancy used the very familiar ploy of inserting a local place-name or concept into a song to give it a local reference. This is the method that I am characterising here as an earlier way of making an English song Australian, a recognition of 'otherness' (here Britishness), and the quick and effective way of turning it round to say this could be Australian too. The shock of recognition and delight that enchanted the audience when Nancy changed the text of 'Dance to Your Daddy' shows just how effective this simple technique can be. In place of 'you shall have a fishy', Nancy sang 'you shall have a flathead', bringing in the name of an Australian fish. 
The technique is well illustrated in the project called Song Links (2003), a double CD that gives English versions of songs in one CD, and the corresponding Australian versions in the other. The change from 'The Banks of the Nile' to 'The Banks of the Condamine' illustrates this. The substitution of the Australian river into the title and the reworking of the text turn this English song into an Australian one, but the closeness of the relationship between the two songs is deliberate and quite clear. 'Oh hark the drums are beating love' becomes 'Oh hark the dogs are barking love', and the preservation of the sentiment of the song is reinforced by very clear textual references to the English version.

However, a more complex relationship to traditional music can be found in Nancy's own songs on Twice Reflected Sun. The first line of her 'Lover's Hymn' with its text 'You'd be a pilgrim' references musically and textually the last line of the hymn 'He Who Would Valiant Be'. This hymn first appeared in The English Hymnal of 1906 (Dearmer and Vaughan Williams 1906). It uses a modified text of John Bunyan's and a folk tune known as Monk's Gate, which had been recorded by Ralph Vaughan Williams. A familiar song trajectory from folk music to church music and back to folk music again is instanced here. Nancy's 'Lover's Hymn' with her own tune and her multivalent text contains several pointers to the hymn, including the concertina accompaniment, which suggests a reedy church organ. While clearly recalling the hymn, Nancy gives the religious concepts 'pilgrim', 'anthem', and 'communion' a new context. The end point of this pilgrimage is 'the home and all its meaning'.

At the National Folk Festival, Nancy said that her song 'Hauling On' was related to the British folk song called 'The Cruel Ship's Captain', about a ship's captain who murdered an apprentice. Nancy's text is appropriately dark: 'Every soul lost to salvation ... bidding life adieu adieu'. Like many of Nancy's songs, however, the text is full of glancing references. Her CD notes suggest that the crew's conscience might be following the ship in the guise of a shark. The song includes a chorus sung at the beginning and the end without accompaniment, and informal reviews found on the Internet suggest that it may well find life as a chorus song. In this it would resemble a sea shanty. 


\section{References to earlier musicians}

In some cases, the appropriation of the tradition is accomplished by simply naming earlier traditional musicians. Respected musicians are given homage in both CDs. Kate has 'Angel and Mr. Cash', referencing June Carter and Johnny Cash, and the piano accompaniment also recalls Joni Mitchell. Nancy has 'Sweet Peace', 'dedicated to Pete Seeger for his ninetieth birthday'. Sparingly accompanied, the song recalls Seeger, not only in its text emphasising issues that he was concerned with, but also in sound, echoing the way Seeger could make a single voice and banjo sound like a perfectly full, rounded, and complete ensemble. 'Rammed Earth' is labelled 'for Charles Darwin', and includes the name of his wife 'Wedgewood', which suggests the eyes Nancy describes were blue. The reference here is not just to music, but extends to wider intellectual traditions. Within their own highly individual compositions and performances, Nancy and Kate use their detailed knowledge and experience of traditional repertoires to bounce off traditional concerns and forms and create expressivities clearly their own. While the songs are their own highly original re-workings, their heritage is clearly on display.

\section{Theoretical observations about place}

Thinking about place and identity, I find these two CDs interesting and thought-provoking in their definition of and relation to place. Identity is not only about place, but place is certainly a large component of it. There is now a great deal of work in Western intellectual traditions in examining the concept of place, and I find the philosopher Edward S. Casey outlines a useful way to think about it.

In his article entitled 'How to Get from Space to Place in a Fairly Short Stretch of Time', Casey argues that the lived body and the experienced place are inseparable (Casey 1996). Bodily sensations are always perceived in a place. They cannot be without a place. He says, 'Just as there are no places without bodies that sustain and vivify them, so there are no lived bodies without the places they inhabit and traverse ... Bodies and places are connatural terms. They interanimate each other' (ibid.: 24).

Casey's second observation is that places collect things, where things refer to 'various animate and inanimate entities' (Casey 1996: 24) and also 'experiences, and histories, even languages and thoughts' (ibid.), 
instancing Aboriginal Australia as an 'intensely gathered landscape' (ibid.: 25). Thousands of traditional Aboriginal songs are closely related to named places. Sometimes the songs can only be properly sung at the actual place named. In their monograph Singing Saltwater Country: Journey to the Songlines of Carpentaria (2010), John Bradley and Yanyuwa families give an accessible but not over-simplified account of some of the Yanyuwa song series that cover their country with names and stories.

For Casey, therefore, a place is in a constant state of invention and understanding. The tight connection he makes between place and process is important. 'Places not only are, they happen' as the 'physical, spiritual, cultural and social' qualities of the lived bodies in place become part of the constitution of the place itself (Casey 1996: 27). These qualities, he notes, cannot exist without place; they are always in place. He cautions against reductionism in considering place in a paragraph expressing clearly the fascination of places:

the endemic status of culture-pervading bodies and places and bodiesin-places-is matched by the equally endemic insinuation of 'wild Being' into the body/place matrix. Even the most culturally saturated place retains a factor of wildness, that is, of the radically amorphous and unaccounted for, something that is not so much immune to culture as alien to it in its very midst, disparate from it from within. We sense this wildness explicitly in moments of absurdity—and of 'surdity', sheer 'thisness'. But it is immanent in every perceptual experience and thus in every bodily insertion into the perceived places anchoring each such experience. This ontological wildness-not to be confused with literal wilderness, much less with mere lack of cultivation-ensures that cultural analysis never exhausts a given place. Just as we should not fall into a perceptualism that leaves no room for expressivity and language, so we ought not to espouse a culturalism that accords no autochthonous being to places, no alterity. In the very heart of the most sophisticated circumstance is a wildness that no culture can contain or explain, much less reduce. This wildness exceeds the scope of the most subtle set of signifiers, despite the efforts of painters to capture it in images and of story tellers to depict it in words. (Casey 1996: 35)

The alterity Casey describes, the wildness that has nothing to do with wilderness, is crucial to the singing I am considering. It is often this alterity and the wonderment it evokes, sitting alongside the emplaced culture, that prompts singers and songwriters to pin their songs to places. In a befitting way, songs and singing have at their core something 
that cannot be expressed in words. Ultimately, their expressivity is all their own, and like the alien 'thisness' of places will always beckon and finally baffle.

Casey notes the porosity of boundaries and talks of 'the role of the lived body as the mediatrix between enculturation and emplacement' (Casey 1996: 44). Basso, in the same volume, also stresses place and process. He quotes Camus's observation that a 'sense of place is not just something that people know and feel, it is something people do' (Basso 1996: 83).

\section{The awkward relationship between British and Indigenous Australian songs of place}

Place often sits awkwardly in non-Indigenous Australian songs. NonIndigenous Australian music and culture are closely associated with those of Britain and North America, but these influences are often very uncomfortable in Australia. Only gradually and recently have nonAboriginal Australians come close to understanding the sense of place that anchors Indigenous cultures. Only gradually and recently have non-Aboriginal Australians come close to recognising and accepting the generosity of Indigenous Australians who have sought for years to explain their country and to offer their understanding to all Australians. This is not to disparage work done by anthropologists over the last century and a half, but to observe the contrast between, for example, Ronald and Catherine Berndt's Man, Land and Myth in North Australia: The Gunwinggu People (1970) and two books published 40 years later: Margaret Somerville and Tony Perkins's Singing the Coast (2011) and John Bradley with Yanyuwa families' Singing Saltwater Country: Journey to the Songlines of Carpentaria (2010).

The Berndts' volume sets out in academically rigorous detail the theory and practices of the man/land relationship in a particular area of Arnhem Land. In the 1970s, I found this account fascinating, but the two recent books touch the reader (at least this reader) in a much more visceral way. They deal with much the same relationships as in the Berndts' volume, but they both anchor the accounts by exploring singing and song, telling of actual people who are named and photographed, and using beautifully drawn maps and illustrations, and personal and poetic descriptions. The Berndts may have had very good reasons for labelling their photographs the way they did, as, for example, 'Gunwinggu man, Oenpelli, 1960', but it allows only a distant and depersonalised view of 
their data. Since the 1960s, the relationship between the non-Indigenous researchers and the people they worked with has changed. The Berndts did their work over many years in many different areas of Australia and Papua New Guinea. In Singing Saltwater Country, John Bradley describes a 30year relationship with Yanyuwa. In Singing the Coast, 10 years of journal entries are drawn on. I take these long years of association as evidence of the Indigenous communities discussed in these two publications drawing researchers into their world, opening it up for them, and making issues in their lives real and demanding for the researchers.

The aching realisation of the loss of Indigenous cultures permeates much of the writing about Indigenous cultures, and, among the extensive writings on this topic, both Singing the Saltwater Country and Singing the Coast are lyrical in their descriptions, and stinging in their sense of loss. John Bradley describes the way his involvement with Yanyuwa families gradually shaped his understanding of the concept of kujika (song lines) and the depth of their relationship to country:

To know country intimately, so intimately that calling its name can cause it to tremble, is a powerful way of knowing. Does the country tremble with joy because a countryman, a relative has heard it, recognised it, remembered it-and so can never ignore it? Such a way of thinking brings another understanding to the power of the kujika: if simply calling its name causes country to tremble, then singing it-with its multiple verses, variations and visceral rhythms - must be for the country, as at times for the singers, an ecstatic experience. (Bradley and Yanuwa families 2010: 194)

Chapters 7 ('Broken songs') and 8 ('It makes the country tremble') address situations where it is feared the songs will be lost as old people die. Because of the intimate relationship between song and place, which is instanced in the above quote, losing the songs is not just a matter of losing culture, it reverberates physically in the land.

Margaret Somerville and Tony Perkins's book is full of poetic response to place:

The beach is edgy this morning. Lumpy, grey clouds, thick like porridge as I face the roaring sea, wind pounding in my ears. I hear the crash of the waves' constant movement but along the water's edge, the space inbetween dry and wet, the smoothed-out sand is still and glassy as each wave retreats. (Somerville and Perkins 2011: 141) 
They note:

These songs are not only about singing the country for Aboriginal people; they are about singing the country for all of us ... We need to make songs that are sad and painful, a requiem for what has happened in the past. We need to sing songs that are joyous, that celebrate the survival and rebirth of Aboriginal peoples. And we need to sing songs that express our love, that beat with the rhythm of our hearts for this country. (Somerville and Perkins 2011:23)

Somerville and Perkins see loss and renewal. There is sadness, 'the last ceremony was in the late 1950s' (Sommerville and Perkins 2011: 214), but there is also a difficult sort of potential.

It is challenging to write about this partial and incomplete knowledge. It is hard to write the sense of the missing bits, the importance of silence and of respecting what cannot be said. It is important to tell these partial stories in a way that they are not experienced only as absence but as fertile potential. (Somerville and Perkins 2011: 123)

Non-Indigenous Australians often see Aboriginal senses of place as reflecting 'mankind's holistic relationships to land, to nature as a whole, and to the spiritual world' (anon. pers. comm.). I am not embracing such sweeping descriptions in this chapter. What I find attractive about Indigenous senses of place in this context is their specificity, their groundedness in particular named places. I used the Bradley with Yanyuwa families and the Somerville and Perkins monographs precisely because of their illumination of very defined places. Bradley with Yanyuwa families, in particular, includes detailed maps of the Gulf regions where he worked, listing and showing the positions of dozens of named places. The sense of place in both these books is not an empty generalisation. It is the opposite: a demonstrable, substantive ground.

\section{Britain and Australia: The blurring of musical boundaries}

These writers-John Bradley and the Yanyuwa families, Margaret Somerville and Tony Perkins-exhort us to sing. Along with the recognition of and mourning for the loss of Indigenous songs, they stress the necessity for Australians to sing about country. These strictures are being heard. Ways to sing about and make music about Australia, to sing 
Australian into being, are being sought in all genres. Some, like Gurrumul Yunupingu and William Barton and the Song Company, are doing work that draws on Indigenous cultures, work that is breathtaking in its originality and execution, and deserving of the plaudits they have won. Other inheritances are not, and should not be, ignored. The Fagan family draws on Australian, British, and North American musical traditions, but my contention here is that musical boundaries are being blurred, that on these recordings Kate and Nancy are not so much singing Australian songs, and British songs, and North American songs, but are using all those resources in ways that canvass new ways of being Australian. Their beingAustralian encompasses being-in-Britain and being-in-North-America in ways that have only become possible in the early twenty-first century. The ease and frequency of long-distance travel allows the possibility of being in multiple places within short time frames, and therefore having intense relationships with far-distant places. My own family gives a physical representation of the distinction I am drawing between the limited choices of country previously available and the freedom of movement now allowed, and I think it is not unusual. My father left England in 1919 and did not return until 1972, 53 years later. My daughter, on the other hand, has lived in England for seven years, but in that time has returned to Australia six times. Within two generations, the experiences of beingin-country have radically altered. I am here conflating the Indigenous practices - which stress the importance of being in a particular place, going to particular places, and, while there, singing them into being-and the new possibility of frequently being in another place.

With earlier Australian folk singers, who would sing songs from their family's homeland as well as songs about Australia, there is a discreteness about different parts of their repertoire. For example, in examining Sally Sloane's repertoire, Graham Seal is able to define four distinct streams: British broadside ballads, older ballads drawing on ancient stories, Australian traditional material, and popular music of the late nineteenth and early twentieth centuries (Seal 2003: 143). Similarly, the 2003 project called Song Links, already mentioned and widely supported by folk music communities in England and Australia, looks at the way British material has been used in Australia.

Kate and James Fagan and Nancy Kerr sing thoughtfully and beautifully about people and places, Australian, British, and American. They explore musically and intellectually what it means to be living in these places and in this way, but the material seems to me to be worked in new ways. 
There are no clear boundaries between Australian, British, and American songs, nor is the material a melange, a melting pot in which individual ingredients lose their character. It is more like a Chinese steamboat, a dish where separate ingredients are cooked in the same pot, not mixing together, but retaining their individuality in the shared medium. No doubt the ready availability of sound and video recordings of other musical traditions, both current and past, has facilitated a deeper understanding of musical cultures that were once remote. Careful study of earlier repertoires enables a better understanding of the songs, their performance and their meaning. A more appropriate 'habitus of listening' develops, and this allows contemporary references to songs, traditions, people, and places to demonstrate a more rigorous integrity. Kate's and Nancy's songs are anchored firmly in particular folk traditions, but their understanding of the whole gamut of songs in English give their performances a range and fluency that has only been available since sound recordings became omnipresent.

\section{Place in the recordings}

Places have a particular force in both these CDs. 'Jerilderie' is one of the most overtly Australian of Nancy's songs. Jerilderie is a small town in southern New South Wales. It is the centre of an agriculture industry that relies on irrigation. It is on the Newell Highway, one of the major roads that traverse New South Wales from north to south. It is associated with the bushranger Ned Kelly's famous letter, a manifesto of 58 pages in which he attempts to justify the actions that made him an outlaw. Wrapped with the Ned Kelly legend and letter, the town revealed itself to Nancy with tough, heart-breaking presence, and her song crystallises that aspect of the town's being. The song's persona of Ned Kelly describes the dust, desert wind, and campfire, and profiles the imagined weariness of the life of the bushranger.

Nancy's song 'Dolerite Skies' draws a connection between Tasmania, which James's mother (and mine also) are associated with, and Northumberland where Nancy's mother lives. The connection is vivified by the presence of dolerite rock in both places. The song also has a dolorous note, with references to 'the end of our world' recalling the age of this continent, and 'the cold tears in the jailyard', where Tasmania's gruesome convict past is invoked. There is an airiness to this song, even though its referents are rock and dust. 
According to Kate's website, 'Clear Water':

is about Lighthouse Beach in the Myall Lake National Park, north of Sydney. I went first to that beach in winter. There was no-one around, only gulls and eagles and the skin of a whale that had beached and been buried. I felt I'd never been anywhere so profound in my life. (Fagan 2012)

Here is the inter-animation Casey describes. Place, body, and song are brought into each other's being. Singing and place come into a relationship that begins to approach the mutual-sacralisation of song and space that Australian Indigenous people evolved. The two publications Singing Saltwater Country (Bradley with Yanyuwa families 2010) and Singing the Coast (Somerville and Perkins 2011) both describe cultures in which song and country vivify each other. Even the titles of the books alert the reader to this central and crucial relationship. To risk oversimplification, when the right person sings the right songs in the right place, the experience is life-enhancing. The singer is strengthened, the song becomes more potent, and the land becomes more fertile. In her song 'Clear Water', and her discussion of it, it seems to me that Kate is approaching this understanding of the interdependence of place and song. In a further reference to Indigenous cultures, Kate balances city and ocean, west and east, and salt water and fresh water, where two contrasting things represent the dualities of Indigenous cultures, and the moiety systems that are at the heart of so much Indigenous thinking.

\section{Travelling}

Casey extends his notion of place to include moving between one place and another, describing the place defined by a journey as 'an area concatenated by peregrinations between the places it connects' (Casey 1996: 24). Moving to places and through places are essential experiences in the definition of place, and the concept of travelling looms very large in both albums. 'The road's my home', Nancy comments in 'Jerilderie', where her experience of the road is associated with the Ned Kelly legend. The dolerite skies blow Nancy home. Home and travelling are everywhere in these songs. 'Queen of Waters', in a springy melody bouncing off a drone in the first verse, talks about travelling home, and the home is described as music-filled, joyous, dancing (like the grasshopper in contrast to the ant), if somewhat lacking in financial resources. 
In Kate's collection I see the long car trips that are so much a part of Australian life. 'Coming to You' so clearly catches the experience of driving long miles. 'Gonna drive to you if it takes all night', she sings, and then the next verse, 'Sun leaves the west horizon', brings clearly to mind tripping up and down the eastern Australian states. Long car journeys through days, and especially through nights, are referenced: the particular experience of moving in an enclosed space through darkness, where blinking lights indicate houses that may not have been visible during the day, and then the moonlight that covers the bush in a grey monochrome. Kate sings 'There's a story for every road' in the song 'O Janey Janey'. The text of this song includes the phrase 'diamond wheel', which Kate uses for the title of the $\mathrm{CD}$. The vocal production here is very deliberate. The vocal attack is very strong, but unstressed notes fall away. The repetition of the minor third drives home the riddling text: 'There was a blind man and he could see'. Together with the banjo accompaniment and the familiar AABA form, this song has an energy and forcefulness that contrasts with some of the more reflective songs. 'Roll You Sweet Rain' also invokes the road: 'We have to keep travelling the road that is under our feet'. The very Australian experience of the sweetness of rain after long drought is lightly and affectionately sung here.

\section{Home}

The elusive concept of 'home', as a state contrasting with all the travelling, is somewhat ambiguous here. In Nancy's collection, 'home' provides the frame. The first song, 'Queen of Waters', farewells one home, extolling it, and at the same time pointing out its deficiencies: 'hail home, hearts that long for the land'. The concluding song, she told us, is partly about all the rammed earth homes she found in Australia (rammed earth homes are made of earth, clay, gravel, or other natural raw materials). Here again 'rammed earth and cool walls shelter our hearts and counter our falls'. Home is a place of rest and refuge, but you cannot stay there. The lives these musicians live force them into travelling, by road or by air, as in Kate's 'Closer I Get to Light'.

In this song, her ambivalence is even clearer: 'A light on for you here ... When you're home from your diamond town', but in other songs the alternative is beckoning. In 'Coming to You', the destination is not home, but a place to be newly discovered: 'We'll find a blanket, a bottle of wine and a place where the water's inviting'. In 'Dollar Bills and Diamond 
Towns', she says, 'I've been living like a road train, but I want to slow down'. In 'Good Morning Mellow', 'gotta get back to the road'. Finally she admits, in 'Roll You Sweet Rain' that 'there ain't no home but the one that goes with you'. There is a consolation though: this home is 'strong as a great wall of stone'.

I contend that the travelling life that used to belong to musicians, sailors, and a few other vocations is now experienced much more widely. Lives now move much more freely between countries. Boundaries between places are not so immutable: they become blurred with frequent crossing. These two CDs demonstrate both in song text and in musical style an easy familiarity with different places and different musical styles. These musicians blend musics not into the placeless emotional states often addressed in popular music, but with considered and appropriate understanding and acknowledgement into stylish, complex, grounded songs.

\section{Conclusion}

Explanation for the way I hear these songs is to be found partly in the song performances themselves, and partly in my own musical heritage. My observation is that the two CDs can both be seen as tied to heritage and identity. In some ways they are very similar and in other ways completely different. Major similarities are to be found, for example, in their orientation to particular kinds of traditional music. This is not a perfunctory obeisance towards what might be thought of as folk song, but a careful, knowledgeable exploration and use of musical styles accessed within their own family traditions and in recordings and performances of others. I have looked at places, people, travelling, and home, and shown how both CDs work with these concepts in subject matter and in musical style. It is not just that these songs are 'about' these things. It is in singing these things that their nature is accomplished. The Indigenous view that the land and its fruits have to be sung into existence is before me here.

There are differences, however, between the two collections. Nancy's songs often have a substantial persona at the front, and the subtleties, glancing references, and complications come behind this front. Kate's songs are sometimes more clearly reflective, with the singing persona more hidden. Although the sound palettes have similarities, they are quite distinctive in musical style. A young woman's voice clearly predominates, 
but there are differences in accompanying instruments. Nancy has her fiddle and viola and James's bouzouki and other plucked strings as the major accompanying instruments, and the character of the performances on these instruments is a major stylistic resource. Nancy's bowed strings are smooth and eloquent, and her voice has a matching smoothness and eloquence. James's bouzouki is strong and energetic, often as in 'Queen of Waters', with a kick on an offbeat that gives considerable rhythmic drive to the performance. Nancy and James shorten and lengthen phrases as needed. They deal with irregular bars and move rhythmic accents around with ease and conviction. Kate has more instruments, although still mostly plucked strings, sometimes electric, and with the addition of Hammond organ and percussion.

The two women's voices are used quite differently. Nancy's is clean and smooth throughout her register. The ease and consistency match her fiddle playing. She uses decorative mordents at well-considered places, for example on the first syllable of 'Persian queen' in 'Queen of Waters'. Sometimes her string technique recalls for me her mother's concertina playing. The staccato in the introduction to 'I Am the Fox' bounces like Sandra's concertina; and the slight pulsing of final notes, as in 'Queen of Waters', echoes the slight push on the bellows that is so characteristic of concertina accents.

Kate varies her tone and dynamics much more. In 'Closer I Get to Light', for example, vocal phrases fade away unless they are finals. Some notes have a falling release at the ends of phrases, like 'ground' in the final verse. The line following that-'And the further I get from running'-moves into a head voice with deliberate effect. Contrasting vocal timbres are heard elsewhere. 'One More Drive', identifying an interplay between driving, living, and loving, uses the melodically isolated high notes to bring a very particular emphasis to the song text. Vocal quality is also differentiated. 'O Janey Janey' has none of the softness of 'Closer I Get to Light' but a hard, edgy quality that gives the song so much bite. The breathiness of the phrase 'dragged you inside' in 'Child upon the Road' is another place where vocal production underscores the song text. In 'Coming to You', the voice and the slide guitar imitate each other. The voice slides around the notes in a way that seems natural to the slide guitar. The smudging is clearly essential to the temper of the song. Rhythm is also manipulated here. In 'Angel and Mr. Cash', Kate is sometimes emphatically on the beat, and at other times she teases the beat, anticipating and postponing it in playful terms. 
Both women have identified and mastered musical techniques that may be heard throughout traditional repertoires in English. They not only know how to produce them, they use them in considered ways to great effect. For me these songs sing Australia. The now much more porous boundaries of countries are referenced by the porosity of musical styles. Extrapolating from what we know of traditional Indigenous musical cultures, we can be fairly certain that the whole of Australia was crisscrossed by ceremonies and songs that were believed to be necessary to keep the country, and its people, flora, and fauna, alive and strong. While traditions are changing, we can still pay attention to the Indigenous understanding of what country is, what life is and what makes it worth living. We need to refresh and reanimate the country and its people, its flora, and its fauna with songs that explore what it is to be here and live here. The way to do it is by means of honest, thoughtful, and musically imaginative songs like these.

\section{References cited}

Basso, Keith. 1996. 'Wisdom Sits in Places: Notes on a Western Apache Landscape.' In Senses of Place, edited by Steven Feld and Keith H. Basso, 53-90. Santa Fe, New Mexico: School of American Research Press.

Becker, Judith. 2004. Deep Listeners: Music, Emotion, and Trancing. Bloomington and Indianapolis: Indiana University Press.

Berndt, Ronald M., and Catherine H. Berndt. 1970. Man, Land and Myth in North Australia: The Gunwinggu People. Sydney: Ure Smith.

Bradley, John, with Yanyuwa families. 2010. Singing Saltwater Country: Journey to the Songlines of Carpentaria. Crows Nest: Allen and Unwin.

Casey, Edward S. 1996. 'How to Get from Space to Place in a Fairly Short Stretch of Time: Phenomenological Prolegomena.' In Senses of Place, edited by Steven Feld and Keith H. Basso, 13-52. Santa Fe, New Mexico: School of American Research Press.

Child, Francis James. 1882-98. ed. The English and Scottish Popular Ballads. 5 volumes. Boston and New York: Houghton, Mifflin and Company. 
Dearmer, Percy, and Ralph Vaughan Williams. 1906. eds. The English Hymnal. London: Oxford University Press.

Fagan, Kate. 2007. Diamond Wheel. Compact disc. Kate Fagan KF0601.

—_. 2012. [Webpage]. Accessed 2 March 2012. www.katefagan.com.

Gibson, Ross. 2002. Seven Versions of an Australian Badland. St Lucia: University of Queensland Press.

Kerr, Nancy. 2014a. 'In an English City Garden.' Sweet Lovely Nancy (16 February). sweetlovelynancy.wordpress.com.

__. 2014b. 'Magpies, Muses and Makeup.' Sweet Lovely Nancy (21 April). sweetlovelynancy.wordpress.com.

—_. 2014c. 'Nests.' Sweet Lovely Nancy (11 March). sweetlovelynancy. wordpress.com.

Kerr, Nancy, and James Fagan. 2010. Twice Reflected Sun. Compact disc. Navigator 041.

Mackinlay, Elizabeth. 2006. "Memories in the Landscape": The Role of Performance in Naming, Knowing, and Claiming Yanyuwa Country.' Journal of Australian Studies 29 (86): 83-90. doi.org/ 10.1080/14443050509388034.

Meredith, John, and Hugh Anderson. 1967. Folk Songs of Australia and the Men and Women Who Sang Them. Sydney: Ure Smith.

Schnupp, Jan W. H., and Jennifer K. Bisley. 2006. 'On Pitch, the Ear and the Brain of the Beholder: Focus on "Neural Coding of Periodicity in Marmoset Audeitory Cortex".' Journal of Neurophysiology 103 (4): 1708-11. doi.org/10.1152/jn.00182.2010.

Seal, Graham. 2003. 'Sally Sloane: A River of Tradition.' In Verandah Music: Roots of Australian Tradition, edited by Graham Seal and Rob Willis, 143. Curtin, WA: Curtin University Books and Fremantle Arts Centre Press.

Somerville, Margaret, and Tony Perkins. 2010. Singing the Coast: Place and Identity in Australia. Canberra: Aboriginal Studies Press. 
A DISTINCTIVE VOICE IN THE ANTIPODES

Song Links. 2003. Song Links: A Celebration of English Traditional Songs and Their Australian Variants. 2 compact discs. Fellside Recordings FECD176D.

Stewart, Lauren, Katharina von Kriegstein, Jason D. Warren, and Timothy D. Griffiths. 2006. 'Music and the Brain: Disorders of Musical Listening.' Brain 129 (7): 1-21. doi.org/10.1093/brain/awl171. 
This text is taken from A Distinctive Voice in the Antipodes: Essays in Honour of Stephen A. Wild, edited by Kirsty Gillespie, Sally Treloyn and Don Niles, published 2017 by ANU Press, The Australian National University,

Canberra, Australia.

dx.doi.org/10.22459/DVA.07.2017.11 